\title{
Perlita expandida como material cimentício suplementar em argamassas alternativas
}

\author{
Expanded perlite as a supplementary cementitious material in alternative mortars \\ Perlita expandida como material cementante complementario en morteros alternativos
}

\author{
Fernanda Medeiros de Araújo \\ ORCID: https://orcid.org/0000-0001-8278-0618 \\ Universidade Federal Rural do Semi-Árido, Brasil \\ E-mail: fernandaaamdrs@gmail.com \\ Sâmea Valensca Alves Barros \\ ORCID: https://orcid.org/0000-0002-9035-486X \\ Universidade Federal Rural do Semi-Árido, Brasil \\ E-mail: sameavalensca@ufersa.edu.br \\ Fabrícia Nascimento de Oliveira \\ ORCID: https://orcid.org/0000-0002-0333-0035 \\ Universidade Federal Rural do Semi-Árido, Brasil \\ E-mail: fabricia@ufersa.edu.br \\ Marília Pereira de Oliveira \\ ORCID: https://orcid.org/0000-0003-4982-3529 \\ Universidade Federal Rural do Semi-Árido, Brasil \\ E-mail: marilia@ufersa.edu.br \\ Andrea Saraiva de Oliveira \\ ORCID: https://orcid.org/0000-0002-5186-2335 \\ Universidade Federal Rural do Semi-Árido, Brasil \\ E-mail: andrea.saraiva@ufersa.edu.br \\ Gelmires de Araújo Neves \\ ORCID: https://orcid.org/0000-0002-2900-1600 \\ Universidade Federal de Campina Grande, Brasil \\ E-mail: gelmiresneves@gmail.com \\ Maria de Lourdes Xavier de França Neta \\ ORCID: https://orcid.org/0000-0002-4736-857X \\ Universidade Federal do Rio Grande do Norte, Brasil \\ E-mail: maria_xavieer@hotmail.com
}

\begin{abstract}
Resumo
A utilização de argamassas alternativas na construção civil constitui atualmente uma importante ferramenta para tornar o setor sustentável e contribuir com a gestão dos resíduos sólidos gerados pela exploração e comercialização das rochas ornamentais. Nesse contexto, o presente estudo analisou a influência da substituição parcial do cimento Portland pela perlita expandida e moída na resistência à compressão simples de argamassas confeccionadas com agregado oriundo dos resíduos de quartzito. Para tal fim, foi realizada a caracterização fisíca, química e mineralógica dos materiais utilizados e o desempenho mecânico das argamassas estudadas. Determinou-se a granulometria dos resíduos de quartzito e a resistência à compressão simples das argamassas investigadas para o traço determinado no delineamento de mistura. Os resultados mostraram que é viável a substituição parcial proposta nesta pesquisa. Após a análise gráfica e dos coeficientes de variação obtidos para os valores de resistência à compressão simples, concluiu-se que a hipótese levantada contribui para tornar o setor da construção civil sustentável à medida que houve um efeito positivo para o teor de substituição adotado.

Palavras-chave: Resíduos de quartzito; Comportamento mecânico; Perlita expandida; Redução do $\mathrm{CO}_{2}$.

Abstract

The use of alternative mortars in civil construction is currently an important tool to make the sector sustainable and contribute to the management of solid waste generated by the exploration and sale of ornamental stones. In this context, this study analyzed the influence of partial replacement of Portland cement by expanded and ground perlite on the simple compressive strength of mortars made with aggregate from quartzite waste. To this end, the physical, chemical and mineralogical characterization of the materials used and the mechanical performance of the studied mortars were carried out. The granulometry of the quartzite residues and the simple compressive strength of the investigated mortars were determined for the trace determined in the mixture design. The results showed that the partial replacement proposed in this research is viable. After the graphic analysis and the coefficients of variation obtained for the simple compression strength values, it was concluded that the hypothesis raised contributes to making the civil construction sector sustainable as there was a positive effect for the adopted replacement content.
\end{abstract}


Keywords: Quartzite residues; Mechanical behavior; Expanded perlite; $\mathrm{CO}_{2}$ reduction.

\section{Resumen}

El uso de morteros alternativos en la construcción civil es actualmente una herramienta importante para hacer sostenible el sector y contribuir al manejo de los residuos sólidos generados por la exploración y comercialización de piedras ornamentales. En este contexto, este estudio analizó la influencia de la sustitución parcial del cemento Portland por perlita expandida y molida sobre la resistencia a la compresión simple de los morteros elaborados con áridos de residuos de cuarcita. Para ello se llevó a cabo la caracterización física, química y mineralógica de los materiales empleados y el comportamiento mecánico de los morteros estudiados. La granulometría de los residuos de cuarcita y la resistencia a la compresión simple de los morteros investigados se determinaron para la traza determinada en el diseño de la mezcla. Los resultados mostraron que el reemplazo parcial propuesto en esta investigación es viable. Luego del análisis gráfico y los coeficientes de variación obtenidos para los valores de resistencia a la compresión simple, se concluyó que la hipótesis planteada contribuye a hacer sustentable el sector de la construcción civil ya que hubo un efecto positivo para el contenido de reemplazo adoptado.

Palabras clave: Residuos de cuarcita; Comportamiento mecánico; Perlita expandida; Reducción de $\mathrm{CO}_{2}$.

\section{Introdução}

Um dos setores econômicos que mais faz uso dos recursos naturais e apresenta potencial para absorver matérias primas alternativas é o da construção civil (Souza et al., 2019). Este setor busca se tornar sustentável, contribuindo para promover a gestão adequada dos resíduos sólidos gerados pelos diversos setores produtivos (Silva et al., 2019). Logo, percebese a necessidade de desenvolver materiais alternativos, como as argamassas alternativas, que atendam as demandas da construção civil e amenizem os impactos negativos causados pela deposição inadequada dos resíduos sólidos gerados pelos diversos setores produtivos, pois estes passam por técnicas de reciclagem e/ou reaproveitamento que os transformam em matéria-prima absorvida no setor construtivo.

As argamassas alternativas são aquelas que fazem uso de matérias-primas oriundas de resíduos beneficiados (Araújo, 2014). Corroborando com esta definição Goulub e Silva (2017) afirmam são argamassas que se propõem a minimizar os impactos negativos causados pelas diversas indústrias que exploram os recursos naturais e tornam o setor da construção civil sustentável.

Neste contexto, destacam-se as pesquisas sobre o uso dos mais variados resíduos produzidos pela indústria da mineração em matrizes cimentícias a exemplo dos gerados na exploração e beneficiamento das rochas ornamentais. Ademais, ocorre em paralelo investigações que objetivam tornar as empresas que produzem os materiais convencionais usados pela construção civil sustentáveis, a exemplo da indústria cimenteira. À medida que dentre os materiais mais utilizados no mundo está o cimento Portland (Formigoni et al., 2019), que é classificado como cimento hidráulico, tem seu processo de obtenção por meio da pulverização de clínqueres o qual gera uma grande emissão de $\mathrm{CO}_{2}$ (Metha \& Monteiro, 2014).

A produção de cimento Portland é alvo de pesquisas que buscam reduzir a emissão de $\mathrm{CO}_{2}$ gerada pelas indústrias cimenteiras, e assim torná-las mais sustentáveis já que este é um dos materiais mais consumidos no mundo (Yang et al., 2015). Uma das técnicas mais simples e de baixo custo utilizadas para reduzir a emissão de $\mathrm{CO}_{2}$ pela indústria cimenteira é a utilização de material cimentício suplementar (MCS) em substituição parcial ao cimento Portland (Hill \& Sharp, 2002). Para que um material possa ser classificado com MCS, de acordo com Rosa et al. (2020), deve apresentar uma granulometria baixa e, geralmente, possuírem efeito pozolânico e/ou cimentante.

Vislumbrando-se as lacunas existentes na literatura quanto a junção das investigações individuais mencionadas acima, percebeu-se a importância de uni-las em uma só pesquisa. Tendendo promover a gestão dos resíduos sólidos gerados na exploração e beneficiamento das rochas de quartzito e reduzir a emissão de $\mathrm{CO}_{2}$ na produção do cimento Portland, investigando o uso de um material já comercializado e de baixo custo como material cimentício suplementar (MCS) em um traço determinado no planejamento experimental desenvolvido por Barros et al. (2016) para argamassas confeccionadas com 
resíduos de quartzito.

O quartzito é uma rocha ornamental que apresenta elevada dureza; grande beleza; não retém água; alta resistência ao aquecimento solar, e é encontrada em abundância na Paraíba, destacando-se a exploração e comercialização no município de Várzea/PB. Nos processos de exploração e beneficiamento do quartzito ocorre a geração de resíduos sólidos com granulometrias distintas, sendo eles descartados indevidamente na natureza, comprometendo o meio ambiente (Júnior et al., 2018). Estes quando são beneficiados pelos processos de moagem e peneiramento adquirem granulometria que permitem serem utilizados como agregado miúdo em argamassas.

A perlita expandida por sua vez é considerada um material pozolânico com alto desempenho, ou seja, pode ser usado para substituir parcialmente o cimento na formação de argamassa, e assim, contribuir para diminuição da emissão de $\mathrm{CO}_{2}$ no meio ambiente já que reduz a quantidade de cimento a ser utilizado (Kotwica et al., 2017).

Os materiais pozolânicos são definidos como materiais silicosos ou sílico-aluminosos, que contém um elevado teor de sílica amorfa, e podem ser classificados em: naturais, quando precisam apenas da moagem para apresentar atividade pozolânica; e artificiais quando são produzidas já com a característica pozolânica, como as escórias metalúrgicas (Montanheiro et al., 2002).

Nesta perspectiva, o presente estudo teve como objetivo investigar o efeito da substituição parcial do cimento Portland pela perlita expandida no comportamento mecânico de argamassas confeccionadas com resíduos de quartzito em substituição total ao agregado convencional, sendo o parâmetro analisado a resistência à compressão simples dessas argamassas.

\section{Materiais e Métodos}

Os materiais utilizados foram: cimento Portland CP V ARI MAX da Nacional; perlita expandida e resíduos de quartzito. A escolha do cimento foi feita por não conter adição de pozolana em sua composição química (Tabela 1).

Tabela 1. Composição química cimento Portland CP V ARI MAX.

\begin{tabular}{|c|c|c|c|c|c|c|c|c|c|c|c|c|}
\hline Material & $\begin{array}{l}\mathrm{CaO} \\
(\%)\end{array}$ & $\begin{array}{l}\mathrm{SiO}_{2} \\
(\%)\end{array}$ & $\begin{array}{l}\mathrm{MgO} \\
(\%)\end{array}$ & $\begin{array}{l}\mathrm{Al}_{2} \mathrm{O}_{3} \\
(\%)\end{array}$ & $\begin{array}{l}\mathrm{Fe}_{2} \mathrm{O}_{3} \\
(\%)\end{array}$ & $\begin{array}{l}\mathrm{SO}_{3} \\
(\%)\end{array}$ & $\begin{array}{l}\mathrm{K}_{2} \mathrm{O} \\
(\%)\end{array}$ & $\begin{array}{l}\mathrm{TiO}_{2} \\
(\%)\end{array}$ & $\begin{array}{l}\mathrm{P}_{2} \mathrm{O}_{5} \\
(\%)\end{array}$ & $\begin{array}{l}\mathrm{OO}^{\mathrm{a}} \\
(\%)\end{array}$ & $\begin{array}{l}\mathrm{PF}^{\mathrm{b}} \\
(\%)\end{array}$ & $\begin{array}{l}\mathrm{C}_{3} \mathrm{~A}^{\mathrm{c}} \\
(\%)\end{array}$ \\
\hline
\end{tabular}

${ }^{\text {a }}$ OO: Outros óxidos; ${ }^{\mathrm{b}} \mathrm{PF}$ : Perda ao Fogo; ${ }^{\mathrm{c}} \% \mathrm{C}_{3} \mathrm{~A}=2,650\left(\% \mathrm{Al}_{2} \mathrm{O}_{3}\right)-1,692\left(\% \mathrm{Fe}_{2} \mathrm{O}_{3}\right)$. Fonte: Autores (2021).

A perlita expandida utilizada neste trabalho foi oriunda da Empresa Bentonita do Nordeste S.A., localizada no Distrito Industrial de Campina Grande/PB. A mesma passou por beneficiamento, que consistiu na moagem em moinho modelo MA 366 com o objetivo de deixá-la na granulometria de material pulverulento para ser usada como MCS. O teor de substituição parcial ao cimento Portland foi de 15\% no traço determinado no planejamento experimental realizado por Barros et al. (2016), que utilizaram a técnica do delineamento de misturas que gerou as superfícies de resposta indicadas na Figura 1. À medida que esta pesquisa é uma continuação da investigação desenvolvida pelos autores mencionados, com o intuito de ampliar os usos dos resíduos de quartzito e tornar as argamassas alternativas ainda mais sustentáveis, diminuindo o consumo de cimento Portland. 
Figura 1. Superfície de resposta e sua projeção no triângulo de composições para misturas obtidas no modelo simplex-lattice centróide $\{3,2\}$ aumentado com pontos interiores determinado por Barros et al. (2016).
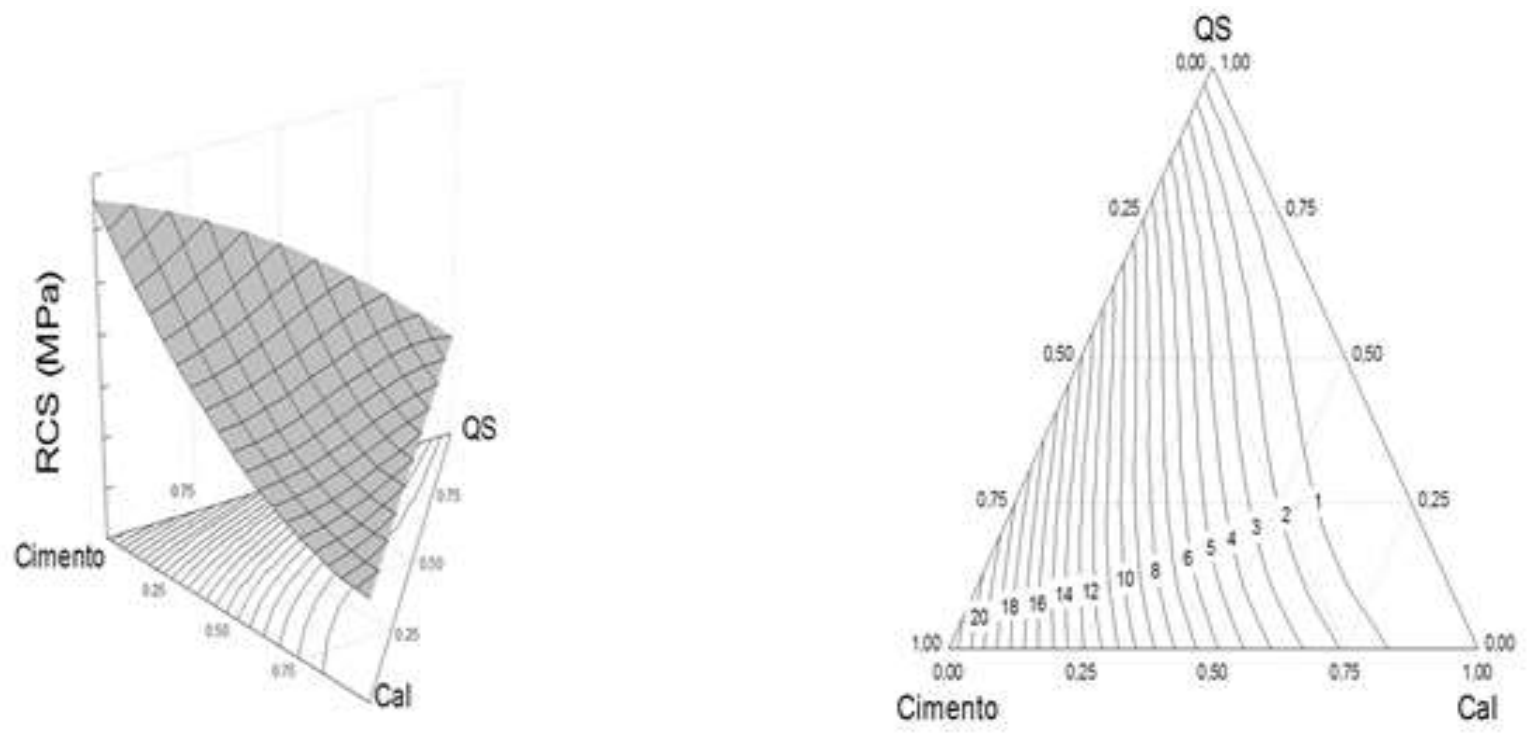

Fonte: Construction and Building Materials (2016).

Verifica-se, nas projeções e no triângulo de composições (Figura 1), que foi definida uma região ótima, na qual se obteve melhores valores de resistência à compressão simples (RCS), e nessa região se encontram os traços 1:3 e 1:1:6. Sendo as misturas com maiores teores de cimento Portland com resistências mais elevadas, de acordo com NBR 13281 (ABNT, 2005), esses valores permitem o uso dessas argamassas alternativas na construção civil. Em decorrência do objetivo desta investigação e da localização do traço 1:3 na região com maiores valores de RCS, o mesmo foi escolhido para o desenvolvimento desta pesquisa com um teor de substituição do cimento Portland pela perlita expandida de $15 \%$.

Já o resíduo de quartzito utilizado foi cedido pela Empresa Tecquímica do Brasil, localizada no município de Várzea/PB. Estes foram utilizados em substituição total ao agregado convencional e já foram cedidos na granulometria utilizada.

Os óxidos presentes na composição química dos materiais utilizados nesta investigação foram determinados por espectrometria de fluorescência de raios X (FRX), com detector EDS (Shimadzu EDX 720). Enquanto, a composição mineralógica foi realizada utilizando difração de raios X (DRX) no Difratômetro Shimadzu XRD-6000 o ângulo $2 \theta$ percorrido foi de $5^{\circ}$ a $60^{\circ}$.

O resíduo de quartzito teve sua caracterização física realizada através da determinação da massa específica aparente conforme a NBR NM 45 (ABNT, 2006), e da granulometria por peneiramento seguindo os procedimentos da NBR NM 248 (ABNT, 2003). Enquanto, a resistência à compressão simples (RCS) foi realizada em Máquina Universal, marca SHIMADZU AG-IS 100KN, de acordo com a NBR 7215 (ABNT, 2019) fazendo uso de corpos de prova cilíndricos com dimensões (50X100) $\mathrm{mm}$.

Esta pesquisa teve caráter metodológico quantitativo pois, de acordo com Pereira et al. (2019), a abordagem quantitativa se caracteriza pelo uso de ensaios para obtenção de grandezas com suas respectivas unidades, que geram conjuntos de dados analisados por técnicas estatísticas, possibilitando a tomada de decisões. 


\section{Resultados e Discussão}

\subsection{Caracterização física, química e mineralógica dos resíduos de quartzito}

$\mathrm{O}$ resíduo de quartzito utilizado nesta pesquisa apresentou massa unitária de $1,33 \mathrm{~g} / \mathrm{cm}^{3}$ sendo classifica como agregado normal, que é indicado para uso em argamassa, de acordo com Bauer (1995). E o teor de finos foi de 1,06\%, logo, este resultado demonstra que o mesmo na granulometria fornecida pode ser utilizado como agregado, à medida que esse teor é considerado baixo e não compromete a obtenção da consistência adequada, não levando a retração e diminuição da resistência das argamassas.

A Tabela 2 apresenta a composição química do resíduo de quartzito, percebe-se que o mesmo apresenta alto teores de sílica e alumina. Os resultados obtidos são semelhantes aos determinados por Carreiro et al. (2016) e por Silva et al. (2018).

Tabela 2. Composição química do resíduo de quartzito.

\begin{tabular}{lccccccccc}
\hline Óxidos & $\mathrm{SiO}_{2}$ & $\mathrm{Al}_{2} \mathrm{O}_{3}$ & $\mathrm{~K}_{2} \mathrm{O}$ & $\mathrm{Fe}_{2} \mathrm{O}_{3}$ & $\mathrm{MgO}$ & $\mathrm{CaO}$ & $\mathrm{S}_{3}$ & $\mathrm{BaO}$ & $\mathrm{PF}$ \\
\hline$(\%)$ & 67,50 & 17,28 & 7,22 & 2,20 & 1,62 & 1,20 & 0,36 & 0,21 & 2,0 \\
\hline \multicolumn{8}{c}{ Fonte: Autores (2021). }
\end{tabular}

Os elevados teores de $\mathrm{SiO}_{2}$ e $\mathrm{Al}_{2} \mathrm{O}_{3}$ (Tabela 2) já eram esperados por se tratar de uma rocha metamórfica, encontra-se também em teores menores óxido alcalino $\left(\mathrm{K}_{2} \mathrm{O}\right)$ e impurezas como o óxido de ferro $\left(\mathrm{Fe}_{2} \mathrm{O}_{3}\right)$. Os resultados obtidos na análise química corroboram com o difatrograma apresentado na Figura 2.

Figura 2. Difatrograma de raios-x do resíduo de quartzito.

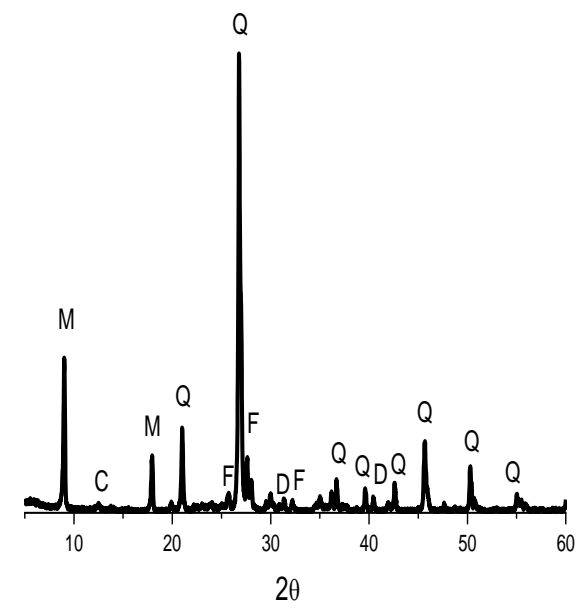

Fonte: Autores (2021).

As seguintes fases mineralógicas foram verificadas no resíduo de quartzito: quartzo (SiO2, JCPDS file: 46-1045); caulinita $\left(\mathrm{Al}_{2} \mathrm{Si}_{2} \mathrm{O}_{5}(\mathrm{OH})_{4}\right.$, JCPDS file: 14-0164); feldspato $\left(\mathrm{KSi}_{3} \mathrm{AlO}_{3}, \mathrm{JCPDS}\right.$ file:84-0710), $\mathrm{mica}_{(\mathrm{KMg}}\left(\mathrm{Si}_{3} \mathrm{Al}\right) \mathrm{O}_{10}(\mathrm{OH})_{2}$, JCPDS file: 83-1808) e dolomita (CaMg $\left(\mathrm{CO}_{3}\right)_{2}$, JCPDS file: 36-046). Estes resultados se assemelharam aos encontrados por Carreiro et al. (2016) e por Silva et al. (2018).

A Figura 3 apresenta a curva granulométrica obtida para o resíduo de quartzito na granulometria fornecida, percebe-se 
que o mesmo pode ser classificado como areia de granulometria continua que contribui para obtenção de argamassas mais trabalháveis e resistentes.

Figura 3. Curva granulométrica do resíduo de quartzito.

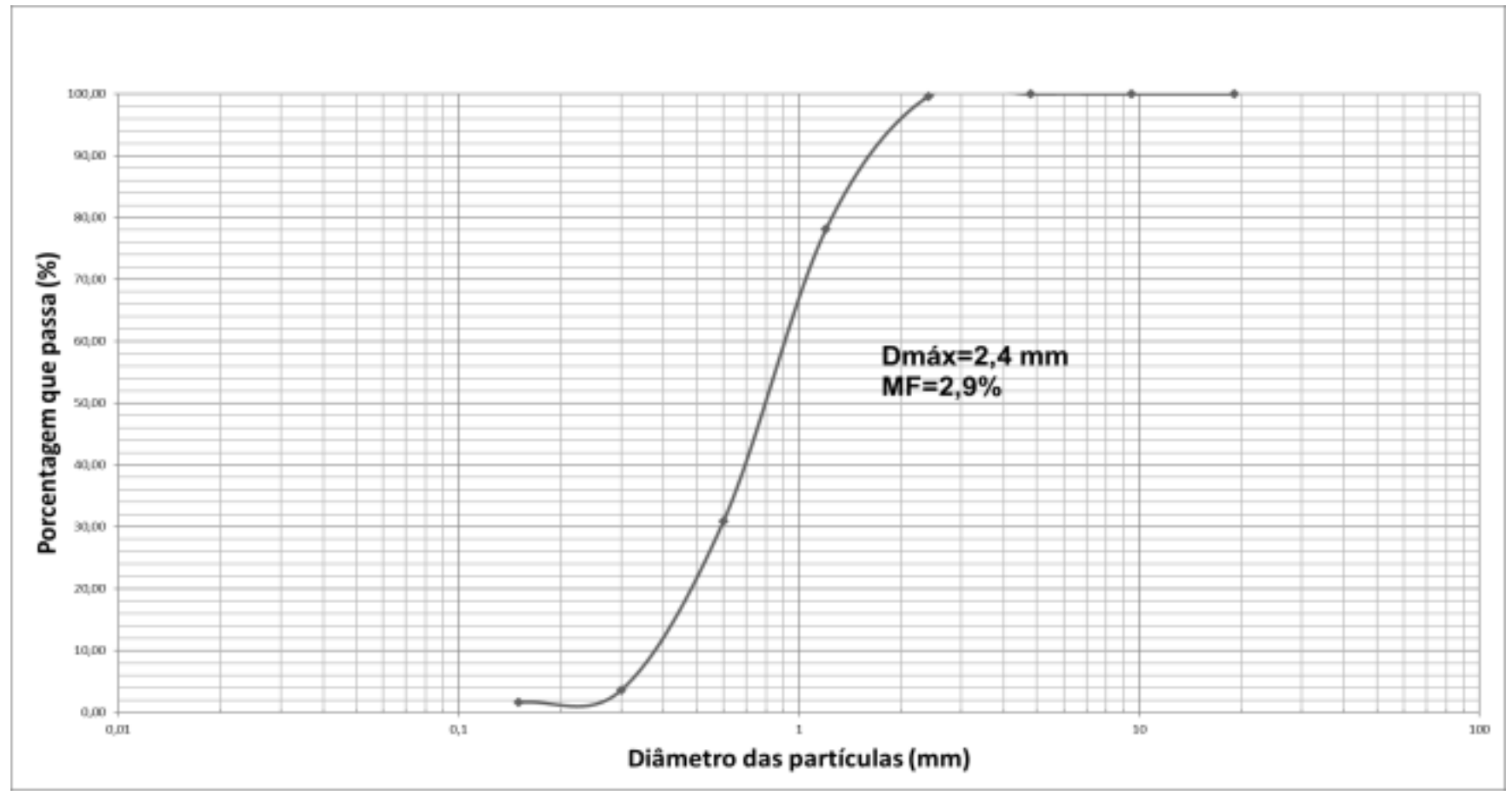

Fonte: Autores (2021).

O comportamento da curva apresentada na Figura 3 corrobora com as considerações realizadas por Carasek et al. (2016), que destacam a influência da composição granulométrica dos agregados no desempenho de argamassas de revestimento.

\subsection{Caracterização química e mineralógica da perlita expandida}

Na Tabela 3 estão contidos os resultados obtidos na determinação da composição química da perlita expandida e moída. Como esperado, apresenta predominância de $\mathrm{SiO}_{2}(71,38 \%)$ e $\mathrm{Al}_{2} \mathrm{O}_{3}(15,05 \%)$. Os valores obtidos nesta pesquisa se assemelham aos determinados por Kotwica et al. (2017).

Tabela 3. Composição química da perlita expandida após moagem.

\begin{tabular}{lcccccccc}
\hline Óxidos & $\mathrm{SiO}_{2}$ & $\mathrm{Al}_{2} \mathrm{O}_{3}$ & $\mathrm{~K}_{2} \mathrm{O}$ & $\mathrm{NaO}_{2}$ & $\mathrm{Fe}_{2} \mathrm{O}_{3}$ & $\mathrm{CaO}$ & $\mathrm{PF}$ & $\mathrm{Eq} \mathrm{NaO}_{2}$ \\
\hline$(\%)$ & 71,38 & 15,05 & 5,18 & 2,32 & 0,76 & 0,89 & 3,90 & 5,73 \\
\hline
\end{tabular}

Fonte: Autores (2021).

A composição química obtida para perlita expandida e moída confirma que a mesma seria classificada como material pozolânico caso o equivalente alcalino em termos de $\mathrm{NaO}_{2}$ não tivesse dado um valor acima do valor máximo permitido (5,73\%), segundo os critérios estabelecidos pela NBR 12653 (ABNT, 2014). Esta norma afirma que um material para ser pozolana deve apresentar a soma percentual de $\mathrm{SiO}_{2}, \mathrm{Al}_{2} \mathrm{O}_{3}$ e $\mathrm{Fe}_{2} \mathrm{O}_{3}$ de no mínimo 70\%, e a perlita expandida e moída apresentou $87,19 \%$ (Tabela 3), a perda ao fogo que não pode passar de 10\% (3,90\%) e a porcentagem de álcalis disponíveis em 
$\mathrm{NaO}_{2}$ máxima de 1,5\% (5,73\%). Este último fator, relaciona-se as reações álcali-agregados e como ultrapassou o máximo permitido não é considerada pozolana, pois pode desencadear estas reações.

Tabela 4. Exigências químicas para materiais pozolânicos.

\begin{tabular}{l|ccc}
\hline \multirow{2}{*}{ Propriedades } & \multicolumn{3}{c}{ Classes de material pozolânico } \\
\cline { 2 - 4 } & $\mathrm{N}$ & $\mathrm{C}$ & $\mathrm{E}$ \\
\hline $\mathrm{SiO}_{2}+\mathrm{Al}_{2} \mathrm{O}_{3}+\mathrm{Fe}_{2} \mathrm{O}_{3}, \%$ mín. & 70 & 70 & 50 \\
Perda ao fogo, \% máx. & 10,0 & 6,0 & 6,0 \\
Álcalis disponíveis em $\mathrm{Na}_{2} \mathrm{O}, \%$ máx. & 1,5 & 1,5 & 1,5 \\
\hline
\end{tabular}

Fonte: Adaptado da NBR 12653 (ABNT, 2014).

A perlita expandida e moída apesar de não poder ser classificada como pozolana, de acordo NBR 12653 (ABNT, 2014), é um material amorfo como se observa no difatrograma obtido para ela (Figura 4). O mesmo se caracteriza pela formação de uma banda larga na faixa entre 15 e $35 \Theta$, que é um indicativo da não cristalinidade da mesma, ou seja, comportamento de material amorfo.

Figura 4. Difatrograma de raios-x da perlita expandida e moída.

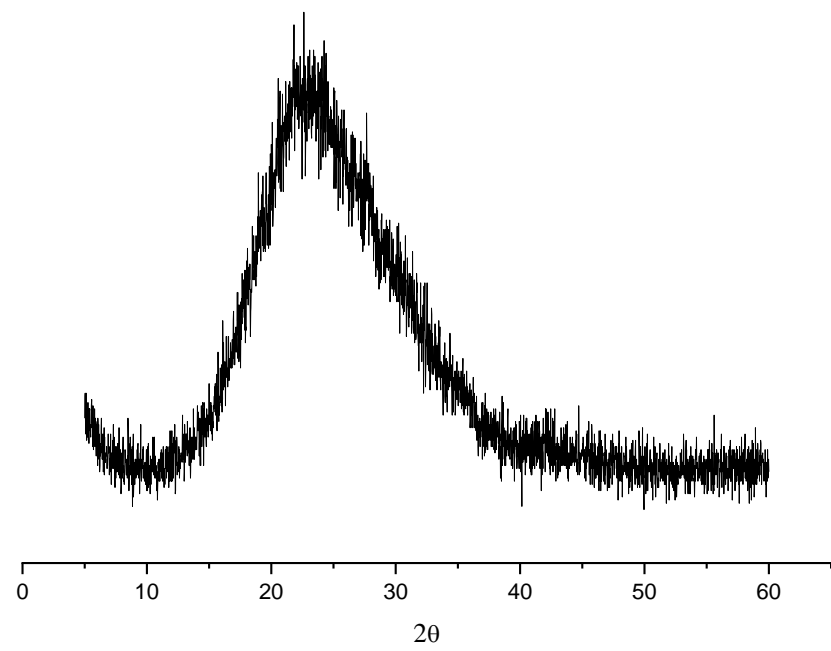

Fonte: Autores (2021).

Mediante os resultados obtidos na caracterização química e mineralógica da perlita expandida e moída, pode-se afirmar que a mesma apesar de ser um material sílico-aluminoso, rico em sílica não cristalina e de origem vulcânica, não é considerado pela NBR 12653 (ABNT, 2014) como pozolana. Porém, estudo de Yu et al. (2003) demonstrou que a mesma apresenta efeito pozolânico quando o parâmetro de análise é o índice de forças utilizado por eles.

Observa-se, ainda, nos resultados alcançados que a sílica presente nos resíduos de quartzito se difere da encontrada na perlita por se apresentar na forma cristalina, enquanto na perlita aparece na forma amorfa. Logo, pela composição química obtida nesta pesquisa podemos classificar o resíduo de quartzito como material sem atividade pozolânica e por isso foi usado como agregado na composição da argamassa. 


\subsection{Desempenho mecânico das argamassas estudadas}

A Tabela 5 apresenta os valores obtidos para resistência à compressão simples (RCS) das argamassas estudadas. Observa-se, na Tabela 5, que os coeficientes de variação obtidos indicam que há uma homogeneidade nos valores de RCS obtidos, fato que nos leva a considerar os resultados representativos.

Tabela 5. RCS das argamassas estudadas.

\begin{tabular}{ccccc}
\hline $\begin{array}{c}\text { Teor de } \\
\text { substituição }(\%)\end{array}$ & $\begin{array}{c}\text { RCS } \\
(\mathrm{MPa})\end{array}$ & $\begin{array}{c}\text { RCS média } \\
(\mathrm{MPa})\end{array}$ & $\begin{array}{c}\text { Desvio Padrão } \\
( \pm)\end{array}$ & $\begin{array}{c}\text { Coeficiente de } \\
\text { variação } \\
(\%)\end{array}$ \\
\hline 0 & 12,97 & & & 4,35 \\
0 & 12,35 & 12,40 & 0,54 & \\
0 & 11,90 & & & 5,98 \\
15 & 14,06 & 13,87 & 0,83 & \\
15 & 14,05 & & & \\
\hline
\end{tabular}

Fonte: Autores (2021).

As argamassas confeccionadas com 15\% de perlita expandida e moída em substituição parcial ao cimento Portland e com agregado oriundo dos resíduos de quartzito apresentaram resistência à compressão simples média aos 28 dias de 13,87MPa. Enquanto, a argamassa de referência (sem perlita expandida e moída) apresentou 12,40MPa. De acordo com a Tabela 6, a argamassa em estudo pode ser classificada como pertencente à classe P6, possuindo assim maior resistência a compressão simples que contribuirá para uma maior durabilidade.

Tabela 6. Classificação das argamassas com relação a resistência a compressão.

\begin{tabular}{cc}
\hline Classe & Resistência a compressão $(\mathrm{MPa})$ \\
\hline P1 & $\leq 2,0$ \\
P2 & 1,5 a 3,0 \\
P3 & 2,5 a 4,5 \\
P4 & 4,0 a 6,5 \\
P5 & 5,5 a 9,0 \\
P6 & $>8,0$ \\
\hline
\end{tabular}

Fonte: Adaptado da NBR 13281 (2005).

Percebeu-se um aumento percentual de 11,85\% que pode ser atribuído ao uso da perlita expandida e moída, demonstrando assim a viabilidade do uso deste percentual em substituição parcial ao cimento Portland. O aumento é ocasionado, provavelmente, porque a sílica, a alumina e o óxido de ferro presente na pozolana, em presença da água, reage com o hidróxido de cálcio e demais componentes do cimento Portland formando compostos estáveis a água e contribuem para uma melhora no comportamento mecânico, tendo como parâmetro a resistência à compressão simples. A Figura 5 apresenta a análise gráfica obtida para os resultados da RCS. 
Figura 5. Análise gráfica dos resultados obtidos.

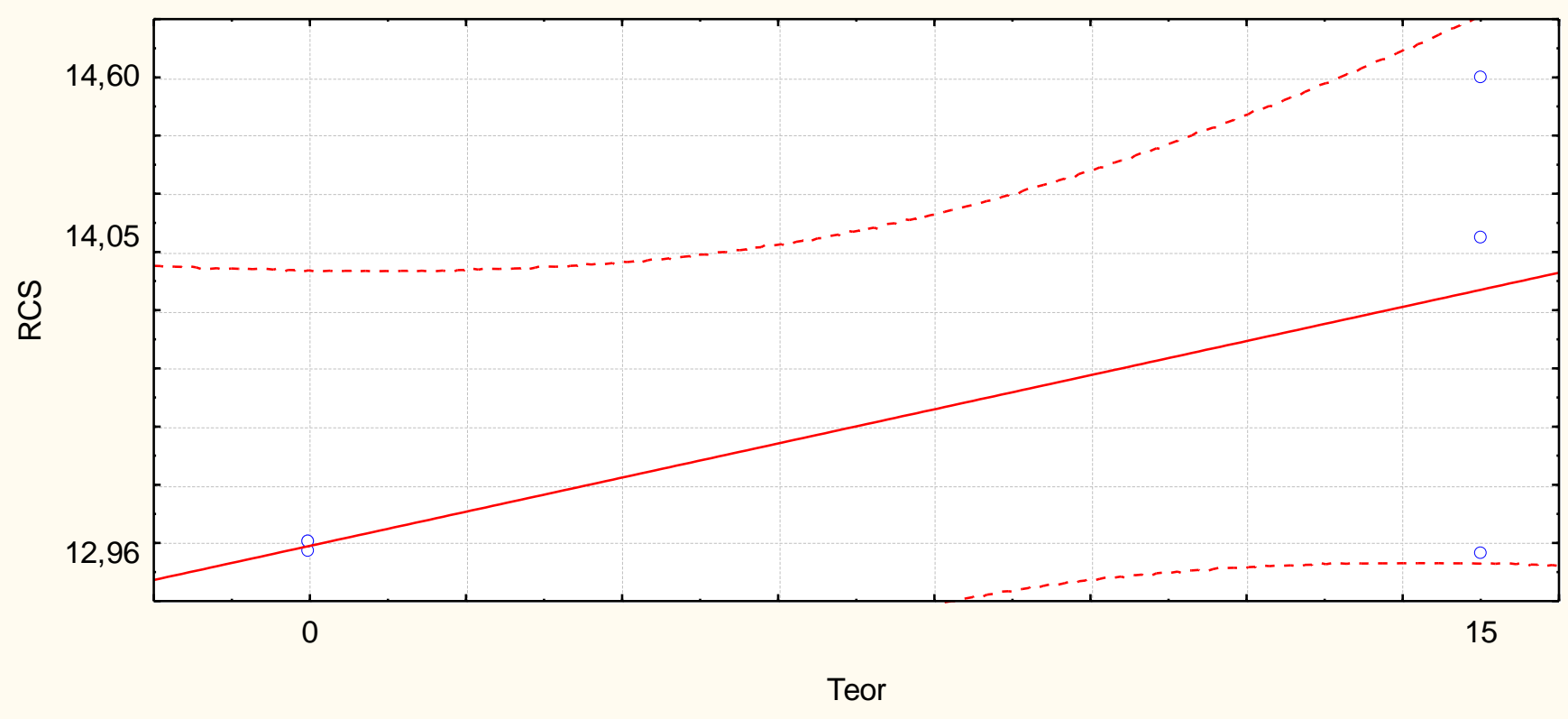

Fonte: Autores (2021).

A Figura 5 demonstra que a RCS aumenta com o aumento do teor de perlita expandida e moída em substituição parcial ao cimento Portland, existindo uma correlação positiva $\mathrm{R}=0,67$ comprovando a hipótese levantada nessa pesquisa.

\section{Conclusão}

Com base nos resultados obtidos nos experimentos, no comportamento das variáveis estudadas, na análise gráfica e na estatística descritiva realizada na presente investigação, conclui-se que o teor de $15 \%$ de substituição parcial do cimento Portland pela perlita expandida e moída proporciona uma melhora no comportamento mecânico das argamassas alternativas confeccionadas com resíduo de quartzito em substituição total ao agregado natural quando o parâmetro considerado é a resistência à compressão simples. E que o efeito positivo, provavelmente, é desencadeado pela presença da sílica amorfa na perlita expandida e moída observada na composição química-mineralógica. Ademais, o resíduo de quartzito apresenta não só a granulometria adequada como outras características que permitem que o mesmo seja utilizado como agregado em argamassas e concretos, a exemplo do baixo teor de finos que evita a ocorrência da retração e contribui para alcançar uma consistência adequada, além de ter proporcionado valores de resistência à compressão simples adequado para argamassas de revestimento.

Como sugestão para pesquisas futuras, percebe-se a importância de investigar o uso da perlita expandida como material cimentício suplementar em argamassas alternativas cujo o agregado seja resíduos oriundos de outros processos produtivos. Ademais, pode-se investigar a durabilidade destas quanto aos ataques químicos já que a perlita expandida e moída apresenta equivalente alcalino de 5,73\%.

\section{Agradecimentos}

Ao CNPq/UFERSA pelo apoio recebido para o desenvolvimento deste trabalho e ao Laboratório de Tecnologia dos Materiais da UFCG por permitir a realização dos ensaios de caracterização química-mineralógica.

\section{Referências}

ABNT. (2019). NBR 7215, 28 de fevereiro de 2019. Cimento Portland - Determinação da resistência à compressão. Associação Brasileira de Normas Técnicas. 
ABNT. (2006). NBR NM 45, 31 de março de 2006. Agregados - Determinação da massa unitária e do volume de vazios. Associação Brasileira de Normas Técnicas.

ABNT. (2003). NBR NM 248, 30 de julho de 2003. Determinação de composição granulométrica dos agregados. Associação Brasileira de Normas Técnicas.

ABNT. (2014). NBR 12653,23 de julho de 2014. Materiais pozolânicos — Requisitos. Associação Brasileira de Normas Técnicas.

ABNT. (2005). NBR 13281, 30 de setembro de 2005. Argamassa para assentamento e revestimento de paredes e tetos — Requisitos. Associação Brasileira de Normas Técnicas

Araújo, N. N. (2014). Desempenho de argamassas de revestimento produzidas com agregados reciclados oriundos do resíduo de construção e demolição da Grande Natal-RN. (Dissertação de mestrado). Programa de Pós-Graduação em Engenharia Civil, Universidade Federal do Rio Grande do Norte.

Abraão, P. C. R. A. (2017). O uso das pozolanas como materiais cimentícios suplementares: disponibilidade, reatividade, demanda de água e indicadores ambientais. (Dissertação de mestrado). Escola Politécnica, Universidade de São Paulo.

Barros, S. V. A., Marciano, J. E. A., Ferreira, H. C., Menezes, R. R., \& Neves, G. A. (2016). Addition of quartizite residues on mortars: Analysis of the alkali aggregate and the mechanical behavior. Construction and Building Materials, 118, 44-351. https://doi.org/10.1016/j.conbuildmat.2016.05.079

Bauer, L. A. F. (1995). Materiais de construção. 1. (5a ed.), LTC.

Carasek, H., Araújo, R. C., Cascudo, O., \& Angelim, R. (2016). Parâmetros da areia que influenciam a consistência e a densidade de massa das argamassas de revestimento. Revista Matéria, 21 (3), 714-732. https://doi.org/10.1590/S1517-707620160003.0068

Carreiro, M. E., Santos, R. C., Silva, V. J., Lira, H. L., Neves, G. A., Menezes, R. R., \& Santana, L. N. L. (2016). Resíduo de quartzito - matéria-prima alternativa para uso em massas de cerâmica estrutura. Cerâmica, 62, 170-178. https://doi.org/10.1590/0366-69132016623621990

Júnior, C. M. D., Neves, G. A., \& Barros, S. V. A. (2018). Utilização de resíduos de quartzito para aplicação em pavimentos intertravados. Revista Eletrônica de Materiais e Processos, 13 (3), 196-200. http://www2.ufcg.edu.br/revista-remap/index.php/REMAP/article/viewFile/687/463

Formigoni, W. F., Godinho, D. S. S., Junca, E., \& Antunes, E. G. P. (2019). Substituição do cimento Portland por resíduo de placa cerâmica em argamassa.

Revista Tecnologia em Metalurgia, Materiais e Mineração, 16 (1), 62-67. http://dx.doi.org/10.4322/2176-1523.20191605

Golub, A., \& Silva, C. V. (2017). Influência do uso de materiais alternativos em argamassa de revestimento interno: avaliação quanto ao isolamento térmico. Perspectiva, 41 (154), 111-126. https://www.uricer.edu.br/site/pdfs/perspectiva/154_628.pdf

Hill, J., \& Sharp, J. H. (2002). The mineralogy and microstructure of three composite cements with high replacement levels. Cement \& Concrete Composites, 24, 191-199. https://doi.org/10.1016/S0958-9465(01)00041-5

Kotwica, Ł., Pichór, W., Kapeluszna, E., \& Różycka, A. (2017). Utilization of waste expanded perlite as new effective supplementary cementitious material. Journal of Cleaner Production, 140, 1344-1352. https://doi.org/10.1016/j.jclepro.2016.10.018

Mehta, P. \& Monteiro, P. (2014). Concreto: microestrutura, propriedades e materiais. (2a ed.), Nicole Pagan Hasparyk.

Montanheiro, T. J., Yamamoto, J. K., Sant'Agostino, L. M., Yushiro, \& K., Saitol, M. M. (2002). Terras Diatomáceas: Uma Pozolana Natural Na Bacia Do Paraná, Estado De São Paulo. Revista do Instituto Geológico, 23 (2), 1-17. https://doi.org/10.5935/0100-929X.20020005

Pereira, A. S., Shitsuka, D. M., Pereira, F. J., Shitsuka, R. (2018). Metodologia do trabalho científico. UFSM. https://repositorio.ufsm.br/bitstream/handle/1 /15824/Lic_Computacao_Metodologia-Pesquisa-Cientifica.pdf?sequence=1\&isAllowed=y

Rosa, L. S., Sousa, K. G. de, Filho, A. R. G., \& Sousa, F. H. F. (2020). Materiais cimentícios suplementares: Histórico e novas tendências. Revista Científica Multidisciplinar Núcleo do Conhecimento, 07, 121-127. https://www.nucleodoconhecimento.com.br/engenharia-civil/materiais-cimenticios

Silva, L. M., Barros, S. A. B., Dantas, G. C. B, \& Pimentel, P. M. (2019). Caracterização de resíduos minerais visando aplicação como agregado para materiais de matriz cimentícia. Revista Construindo, 11 (1), 21-30. http://revista.fumec.br/index.php/construindo/article/view/6651

Silva, K. R., Campos, L. F.A., \& Santana, L. N. L. (2018). Resíduo De Quartzito - Matéria-Prima Alternativa Para Ser Incorporada em Massas Utilizadas na Produção de Grés Porcelanato. Revista Eletrônica de Materiais e Processos, $13 \quad(1)$, 56-63. http://www2.ufcg.edu.br/revistaremap/index.php/REMAP/article/view/656/446

Souza, M. H. O., Neta, M. L. X. F., Barros, S. V. A., Dantas, G. C. B., Neves, G. A., Cartaxo, J. M., \& Pimentel, P. M. (2019). Influência do tipo de cura no comportamento mecânico de argamassas confeccionadas com areia de scheelita. Revista Eletrônica de Materiais e Processos, 14 (2), 91-94. http://www2.ufcg.edu.br/revista-remap/index.php/REMAP/article/viewFile/698/482

Yang, K.-H., Jung, Y. B., Cho, M. S., \& Tae, S. H. (2015). Effect of supplementary cementitious materials on reduction of CO ${ }_{2}$ emissions from concrete. Journal of Cleaner Production, 103, 774-783. https://doi.org/10.1016/j.jclepro.2014.03.018

Yu, L.-H., Ou1, H., Lee \& L.-L. (2003). Investigation on pozzolanic effect of perlite powder in concrete. Cement and Concrete Research, 33 , 73 - 76. https://doi.org/10.1016/S0008-8846(02)00924-9 